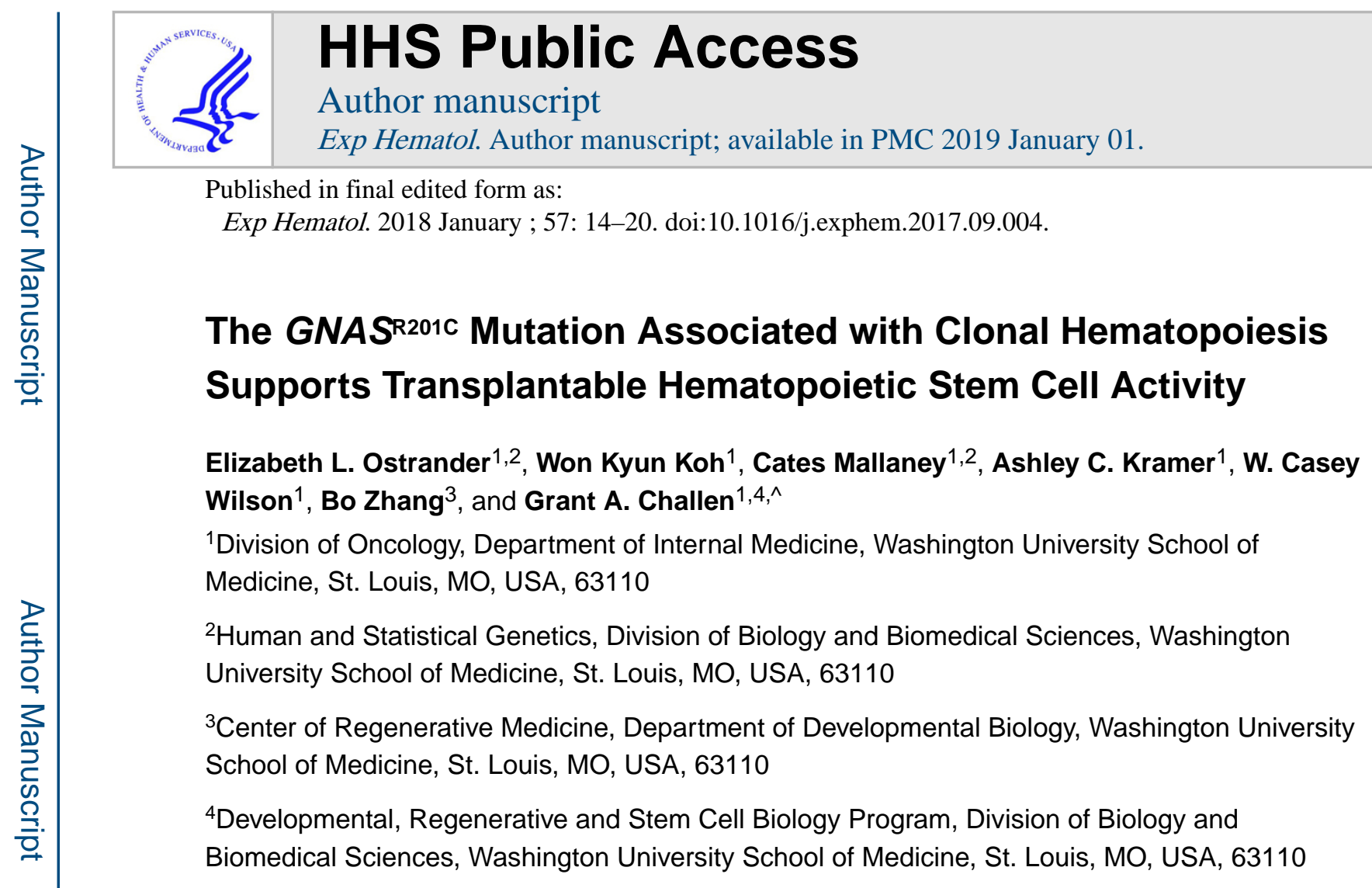

\title{
Abstract
}

Genome sequencing efforts have identified virtually all of the important mutations in adult myeloid malignancies. More recently, population studies have identified cancer-associated variants in the blood of otherwise healthy individuals as they age, a phenomenon termed clonal hematopoiesis of indeterminate potential (CHIP). This suggests these mutations may occur in HSCs long before any clinical presentation, but are not necessarily harbingers of transformation as only a fraction of individuals with CHIP develop hematopoietic pathologies. Delineation between CHIP variants that predispose for disease versus those which are more benign could be used as a prognostic factor to identify individuals more at-risk for transformation. To achieve this, the biological impact of CHIP variants on hematopoietic stem cell (HSC) function must be validated. One variant that has been recurrently identified in CHIP is a gain-of-function missense mutation in the imprinted gene $G N A S$. In this study, we examined the effect of the $G N A S^{\mathrm{R} 201 \mathrm{C}}$ variant on HSC function. Ecoptic expression of $G N A S^{\mathrm{R} 201 \mathrm{C}}$ supported transplantable HSC activity, and improved lymphoid output in secondary recipients. As declining lymphoid output is a hallmark of aging, GNAS $S^{\mathrm{R} 201 \mathrm{C}}$ mutations may sustain lymphoid-biased HSCs over time and maintain them in a developmental state favorable for transformation.

\footnotetext{
^Correspondence: Grant A. Challen, Ph.D., Ph: +1 314-362-0987, Fax: +1 314-747-2797, grantchallen@ wustl.edu, Washington University School of Medicine, 660 Euclid Avenue, St. Louis, MO, USA, 63110.

AUTHORSHIP CONTRIBUTIONS

Designed and performed experiments: E.L.O., W.K.K., A.C.K., W.C.W., G.A.C. Analyzed data: E.L.O, W.K.K., C.M., B.Z., G.A.C. Wrote and edited the paper: E.L.O., G.A.C.

\section{CONFLICT OF INTEREST DISCLOSURES}

The authors declare no competing financial interests.

Publisher's Disclaimer: This is a PDF file of an unedited manuscript that has been accepted for publication. As a service to our customers we are providing this early version of the manuscript. The manuscript will undergo copyediting, typesetting, and review of the resulting proof before it is published in its final citable form. Please note that during the production process errors may be discovered which could affect the content, and all legal disclaimers that apply to the journal pertain.
} 


\section{Keywords}

Hematopoietic Stem Cell; Clonal Hematopoiesis; Somatic Mutation

\section{INTRODUCTION}

Hematopoietic stem cells (HSCs) lose functional capacity with age, with declining output of blood cells (particularly lymphoid cells) on a per-HSC basis [1-4]. In elderly individuals, the hematopoietic system becomes over-represented by the output of select HSCs [5, 6]. This is termed clonal hematopoiesis of indeterminate potential (CHIP) when the HSC clones that come to dominate contain genetic mutations characteristic of acute myeloid leukemia (AML) and myelodysplastic syndromes (MDS). CHIP statistically increases risk for MDS and AML, but also leads to an elevation in all-cause mortality, largely related to cardiovascular events [7-9]. However, as only a fraction of individuals with CHIP develop MDS or AML, it raises the question as to which CHIP-associated variants are predictive of future disease progression. Delineation between individuals with CHIP who are presaged for MDS or AML, versus those who will continue with benign hematopoiesis may provide a window for intervention or prevention of leukemic transformation.

One variant that is recurrently identified in CHIP is an R201C missense mutation in the Guanine Nucleotide Binding Protein, Alpha Stimulating (GNAS) gene [7, 8]. GNAS is an imprinted gene which encodes the stimulatory G-protein alpha subunit $\left(\mathrm{Gs}_{\mathrm{a}}\right)$ which mediates signal transduction from a number of hormones and growth factors [10]. The $G N A S^{\mathrm{R} 201 \mathrm{C}}$ variant confers gain-of-function activity, and somatic $G N A S^{\mathrm{R} 201 \mathrm{C}}$ mutations have been identified in a variety of solid tumors [11-16], and more recently MDS [17-19]. However, $G N A S^{\mathrm{R} 201 \mathrm{C}}$ mutations are more frequent in CHIP than MDS, questioning the oncogenic potential of this mutation. To investigate this, we examined the functional effect of $G N A S^{\mathrm{R} 201 \mathrm{C}}$ in HSCs.

\section{MATERIALS AND METHODS}

\section{Mice, Lentivirus and Transplantation}

Animal procedures were IACUC-approved and conducted in accordance with Washington University institutional guidelines. All mice were C57Bl/6 background. Human $G N A S$ (NM_000516.5) cDNA was cloned into the pMND-IRES-GFP lentiviral vector [20]. The $G N A S^{\mathrm{R} 201 \mathrm{C}}$ variant was generated using the Q5 Site-Directed Mutagenesis Kit (NEB) to create a c.601C $>\mathrm{T}$ nucleotide substitution. Lentiviral transduction, bone marrow transplantation and flow cytometric analysis were performed as previously described [21].

\section{Cell Purification and Flow Cytometry}

Antibody staining was performed as previously described [21]. Proliferation analysis was performed with the APC BrdU Flow kit (BD Biosciences). Apoptosis analysis of bone marrow was performed with the AnnexinV Apoptosis Detection Kit APC (eBioscience). Intracellular staining of 32D cells was performed with the Cytofix/Cytoperm Fixation/ Permeabilization Kit (BD Biosciences) and stained with anti-cleaved PARP (Asp 214; BD) 
and anti-H2A.X phosphor Ser139 (BioLegend). 32D cell growth assays were performed from seeding 50,000 cells then enumerating viable cell number 72-hours later.

\section{Methocult Serial Replating}

Two-days post-transduction, $150 \mathrm{Sca}-1+\mathrm{c}-\mathrm{Kit}+\mathrm{CD} 48-\mathrm{CD} 150+\mathrm{GFP}+$ cells were sorted directly into Methocult M3434 medium (Stem Cell Technologies). Colony-forming units (CFUs) were scored after seven days, then cells were collected and replated at a density of 5,000 cells/well.

\section{RNA-seq and Gene Expression Analysis}

RNA was isolated using the NucleoSpin RNA XS kit (Macherey-Nagel, Bethlehem, PA, USA). Library preparation was performed with $1-5 \mathrm{ng}$ of total RNA using the SMARTer Ultra Low RNA kit (Clontech) and sequenced on an Illumina HiSeq-3000. RNA-seq reads were aligned to the mouse genome (mm10). Gene-level transcript counts were then imported into the R/Bioconductor package EdgeR for differentially expressed gene analysis. Differentially expressed genes were filtered for fold-change $>2$ with false-discovery rate (FDR) $<0.01$. RNA-seq data is available under GEO accession number GSE98487.

\section{Western Blot}

Cells were serum-starved at $37^{\circ} \mathrm{C}$ for 1-hour, then incubated in $10 \mathrm{ng} / \mathrm{ml}$ murine GM-CSF (R\&D Systems) for 10min. Cell lysates were separated on 4-15\% TGX gels (Bio-Rad) and transferred to PVDF Immobilon-P Transfer membranes (Millipore). Antibodies used were against phospho-Erk1/2 (Cell Signaling \#4370), and total Erk1/2 (Cell Signaling \#4695). Membranes were developed using Immobilon Western Chemiluminescent HRP substrate (Millipore) and imaged on a Chemidoc MP system (Bio-Rad).

\section{Statistics}

Student $t$-test and ANOVA's were used for statistical comparisons where appropriate. Significance is indicated on the figures using the following convention: ${ }^{*} p<0.05, * * p<0.01$, $* * * p<0.001$. Error bars on graphs represent the S.E.M.

\section{RESULTS AND DISCUSSION GNAS $^{\text {R201C }}$ Does Not Induce Hematopoietic Disease}

We ectopically expressed $G N A S^{\mathrm{R} 201 \mathrm{C}}$ in mouse bone marrow hematopoietic progenitor cells by lentiviral transduction in parallel with empty vector control (GFP) and wild-type $G N A S$. Serial replating of transduced HSCs demonstrated that $G N A S^{\text {R201C }}$ HSCs sustained colonyforming activity after three passages, in contrast to the other genotypes (Fig. 1A), suggesting $G N A S^{\mathrm{R} 201 \mathrm{C}}$ might enhance HSC self-renewal. To examine this in vivo, bone marrow transplantation of transduced hematopoietic progenitors was performed. Lentiviral transduction produced a 7-fold increase in GNAS expression in HSCs (Fig. 1B), and transduction levels were comparable amongst genotypes (Fig. 1C). Over a one-year observation period, myeloid contribution of $G N A S^{\mathrm{R} 201 \mathrm{C}}$ cells began to decline compared to wild-type $G N A S$ and the empty vector control (Fig. 1D). But apart from a decrease in 
myeloid chimerism, no overt hematopoietic pathologies were observed resulting from ectopic expression of $G N A S^{\mathrm{R} 201 \mathrm{C}}$ in HSCs (Fig. 1E).

\section{GNAS $^{\text {R201C }}$ Supports Transplantable HSC Activity and Preserves Lymphoid Potential}

To more strictly assess the impact of $G N A S^{\mathrm{R} 201 \mathrm{C}}$ on HSC self-renewal, we performed serial bone marrow transplantation. Cohorts of mice were transplanted with transduced bone marrow progenitors. Peripheral blood chimerism over 16-weeks was similar to the prior oneyear transplant cohort (data not shown). Primary recipient mice were sacrificed at 18 -weeks post-transplant for bone marrow isolation. Flow cytometric analysis revealed no difference in the total number of HSCs (Fig. 2A), or the abundance of GFP+ HSCs (Fig. 2B). Interestingly, GNAS ${ }^{\mathrm{R} 201 \mathrm{C}} \mathrm{HSCs}$ were enriched using the most stringent gates for phenotypically-defined HSCs which generally represent the most quiescent long-term HSCs with the most robust repopulating activity (Fig. 2C).

We transferred $3 \times 10^{6}$ whole bone marrow (WBM) cells from individual primary recipients into secondary hosts. Over the 16-week secondary transplant period, GNAS ${ }^{\mathrm{R} 201 \mathrm{C}} \mathrm{HSCs}$ contributed more to T-cell output in the peripheral blood, but less to myeloid differentiation (Fig. 2D). Although there was no difference in the total number of HSCs between these groups of mice (Fig. 2E), there was an increased contribution of GFP+ cells to the HSC compartment in $G N A S^{\mathrm{R} 201 \mathrm{C}}$ recipients. However, we could not observe any differences in the rate of proliferation (Fig. 2G) or apoptosis (Fig. 2H) of transduced HSCs in vivo to explain this phenotype. These data suggest that GNAS $S^{\mathrm{R} 201 \mathrm{C}}$ mutations may help HSCs sustain functional potential over serial transplant, particularly with respect to lymphoid differentiation capacity $[3,4,22]$.

\section{Molecular Pathways Regulated by GNAS ${ }^{R 201 C}$ in HSCs}

We analyzed molecular pathways to understand mechanisms of hematopoietic lineage specification regulated by $G N A S^{\mathrm{R} 201 \mathrm{C}}$. As $G N A S^{\mathrm{R} 201 \mathrm{C}}$ activates Erk1/2 signaling in intestinal tumorigenesis [12], we analyzed this pathway in GFP+ bone marrow cells from secondary recipients. Expression of both $G N A S$ and $G N A S^{\mathrm{R} 201 \mathrm{C}}$ enhanced basal pErk1/2 activity, an effect that was not exacerbated with additional stimulation with cytokines such as GM-CSF (Fig. 3A). We performed gene expression analysis on transduced HSCs to understand the molecular targets affected by $G N A S^{\text {R201C }}$. RNA-seq identified clusters of genes significantly different between HSCs of the different genotypes (Fig. 3B,

Supplementary Table 1). Gene Set Enrichment Analysis (GSEA) revealed that many of the molecular pathways dysregulated were common to both $G N A S$ and $G N A S^{\mathrm{R} 201 \mathrm{C}}$ in comparison to control GFP HSCs, such as a upregulation of Myc targets and interferon response genes (Fig. 3C). As the interferon pathway is an important regulator of HSC function [23, 24], we investigated how $G N A S$ signaling influenced this response by treating $32 \mathrm{D}$ cells stably expressing wild-type $G N A S$ or $G N A S^{\mathrm{R} 201 \mathrm{C}}$ with increasing concentrations of interferon gamma (IFNg). Both cell lines showed the same growth inhibition as the control cell line with increasing IFNg (Fig. 3D). The only pathway that was enriched in $G N A S^{\mathrm{R} 201 \mathrm{C}}$ compared to GNAS HSCs was the unfolded protein response (UPR; Fig. 3E). This pathway maintains the integrity of the HSC pool by eliminating defective HSCs resulting from DNA damage or reactive oxygen species accumulation [25]. The canonical 
UPR gene DNAjb9 (ERDJ4) was specifically upregulated in $G N A S^{\mathrm{R} 201 \mathrm{C}}$ HSCs (Fig. 3F). Ectopic expression of ERDJ4 preserves long-term HSC function by enhancing ER folding capacity and protection against UPR-induced apoptosis [25]. GNAS ${ }^{\mathrm{R} 201 \mathrm{C}}$ mutations may sustain HSCs by uncoupling the UPR during stress (i.e. long-term serial transplant) to preserve cells that may otherwise be marked for apoptosis. We induced an UPR in stable $32 \mathrm{D}$ cell lines by treatment with tunicamycin, but there was no difference in $\mathrm{IC}_{50}$ amongst the genotypes (Fig. 3G). Treatment with $450 \mu \mathrm{g} / \mathrm{mL}$ tunicamycin induced comparable increases in apoptosis across all genotypes (Fig. $3 \mathrm{H}$ ), and there was no difference in the DNA damage response at this dose as determined by proportion of $\gamma \mathrm{H} 2 \mathrm{AX}+$ cells (Fig. 3I).

The mechanisms of how $G N A S^{\mathrm{R} 201 \mathrm{C}}$ mutations preserve long-term HSCs are likely complex and multi-factorial, similar as to how we have shown loss-of-function Dnmt3a mutations produce only minor changes in DNA methylation despite producing a robust enhancement of HSC self-renewal [26, 27]. As we did not observed overt transformation from HSC expressing $G N A S^{\mathrm{R} 201 \mathrm{C}}$, this insinuates this mutation may act to preserve a population of HSCs that have the potential to be disease-founding clones, which are primed for transformation when presented with an appropriate co-operating mutation. Future studies with defined genetic models will be required to comprehensively answer these questions.

\section{Supplementary Material}

Refer to Web version on PubMed Central for supplementary material.

\section{Acknowledgments}

We thank the Alvin J. Siteman Cancer Center at Washington University School of Medicine for the use of the Siteman Flow Cytometry Core, which provided cell sorting and analysis. The Siteman Cancer Center is supported in part by NCI Cancer Center Support Grant CA91842. We thank the Genome Technology Access Center Washington University School of Medicine for genomic analysis. The Center is partially supported by NCI Cancer Center Support Grant CA91842 and by ICTS/CTSA Grant UL1TR000448 NIH, and NIH Roadmap for Medical Research. Research reported in this publication was supported by the Washington University Institute of Clinical and Translational Sciences grant UL1 TR000448 NIH. The content is solely the responsibility of the authors and does not necessarily represent the official view of the NIH. E.L.O was supported by NIH 5T32CA113275-10, C.M. was supported by NIH DK111058-01, and W.C.W. was supported by NIH T32HL007088. This work was supported by grants (to G.A.C.) from the American Society of Hematology, the Edward Mallinckrodt Jr Foundation, the Sidney Kimmel Foundation and V Foundation.

\section{References}

1. Rossi DJ, Bryder D, Zahn JM, et al. Cell intrinsic alterations underlie hematopoietic stem cell aging. Proc Natl Acad Sci U S A. 2005; 102:9194-9199. [PubMed: 15967997]

2. Chambers SM, Shaw CA, Gatza C, Fisk CJ, Donehower LA, Goodell MA. Aging hematopoietic stem cells decline in function and exhibit epigenetic dysregulation. PLoS Biol. 2007; 5:e201. [PubMed: 17676974]

3. Challen GA, Boles NC, Chambers SM, Goodell MA. Distinct hematopoietic stem cell subtypes are differentially regulated by TGF-beta1. Cell Stem Cell. 2010; 6:265-278. [PubMed: 20207229]

4. Dykstra B, Olthof S, Schreuder J, Ritsema M, de Haan G. Clonal analysis reveals multiple functional defects of aged murine hematopoietic stem cells. J Exp Med. 2011; 208:2691-2703. [PubMed: 22110168]

5. Busque L, Mio R, Mattioli J, et al. Nonrandom X-inactivation patterns in normal females: Lyonization ratios vary with age. Blood. 1996; 88:59-65. [PubMed: 8704202] 
6. Busque L, Patel JP, Figueroa ME, et al. Recurrent somatic TET2 mutations in normal elderly individuals with clonal hematopoiesis. Nature Genetics. 2012; 44:1179-1181. [PubMed: 23001125]

7. Xie M, Lu C, Wang J, et al. Age-related mutations associated with clonal hematopoietic expansion and malignancies. Nat Med. 2014; 20:1472-1478. [PubMed: 25326804]

8. Jaiswal S, Fontanillas P, Flannick J, et al. Age-related clonal hematopoiesis associated with adverse outcomes. N Engl J Med. 2014; 371:2488-2498. [PubMed: 25426837]

9. Genovese G, Kahler AK, Handsaker RE, et al. Clonal hematopoiesis and blood-cancer risk inferred from blood DNA sequence. N Engl J Med. 2014; 371:2477-2487. [PubMed: 25426838]

10. Aldred MA, Trembath RC. Activating and inactivating mutations in the human GNAS1 gene. Human mutation. 2000; 16:183-189. [PubMed: 10980525]

11. Song ZJ, Reitman ZJ, Ma ZY, et al. The genome-wide mutational landscape of pituitary adenomas. Cell research. 2016; 26:1255-1259. [PubMed: 27670697]

12. Wilson CH, McIntyre RE, Arends MJ, Adams DJ. The activating mutation R201C in GNAS promotes intestinal tumourigenesis in Apc(Min/+) mice through activation of Wnt and ERK1/2 MAPK pathways. Oncogene. 2010; 29:4567-4575. [PubMed: 20531296]

13. Fecteau RE, Lutterbaugh J, Markowitz SD, Willis J, Guda K. GNAS Mutations Identify a Set of Right-Sided, RAS Mutant, Villous Colon Cancers. PLoS ONE. 2014:9.

14. Sjoblom T, Jones S, Wood LD, et al. The consensus coding sequences of human breast and colorectal cancers. Science. 2006; 314:268-274. [PubMed: 16959974]

15. Lemos MC, Thakker RV. GNAS Mutations in Pseudohypoparathyroidism Type 1a and Related Disorders. Human mutation. 2015; 36:11-19. [PubMed: 25219572]

16. Yoshimoto K, Iwahana H, Fukuda A, Sano T, Itakura M. Rare Mutations of the Gs Alpha-Subunit Gene in Human Endocrine Tumors - Mutation Detection by Polymerase Chain Reaction-PrimerIntroduced Restriction Analysis. Cancer. 1993; 72:1386-1393. [PubMed: 8339229]

17. Bejar R, Stevenson K, Abdel-Wahab O, et al. Clinical Effect of Point Mutations in Myelodysplastic Syndromes. New Engl J Med. 2011; 364:2496-2506. [PubMed: 21714648]

18. Makishima H, Yoshizato T, Yoshida K, et al. Dynamics of clonal evolution in myelodysplastic syndromes. Nature Genetics. 2017; 49:204-212. [PubMed: 27992414]

19. Di Giacomo D, Fernandez AGL, Pierini T, et al. The GNAS1 gene in myelodysplastic syndromes (MDS). Leukemia Res. 2014; 38:804-807. [PubMed: 24795070]

20. Schuettpelz LG, Gopalan PK, Giuste FO, Romine MP, van Os R, Link DC. Kruppel-like factor 7 overexpression suppresses hematopoietic stem and progenitor cell function. Blood. 2012; 120:2981-2989. [PubMed: 22936656]

21. Challen GA, Boles N, Lin KK, Goodell MA. Mouse hematopoietic stem cell identification and analysis. Cytometry A. 2009; 75:14-24. [PubMed: 19023891]

22. Dykstra B, Kent D, Bowie M, et al. Long-term propagation of distinct hematopoietic differentiation programs in vivo. Cell Stem Cell. 2007; 1:218-229. [PubMed: 18371352]

23. Essers MA, Offner S, Blanco-Bose WE, et al. IFNalpha activates dormant haematopoietic stem cells in vivo. Nature. 2009

24. Baldridge MT, King KY, Boles NC, Weksberg DC, Goodell MA. Quiescent haematopoietic stem cells are activated by IFN-gamma in response to chronic infection. Nature. 2010; 465:793-797. [PubMed: 20535209]

25. van Galen P, Kreso A, Mbong N, et al. The unfolded protein response governs integrity of the haematopoietic stem-cell pool during stress. Nature. 2014; 510:268. [PubMed: 24776803]

26. Challen GA, Sun D, Jeong M, et al. Dnmt3a is essential for hematopoietic stem cell differentiation. Nat Genet. 2012; 44:23-31.

27. Challen GA, Sun D, Mayle A, et al. Dnmt3a and Dnmt3b Have Overlapping and Distinct Functions in Hematopoietic Stem Cells. Cell Stem Cell. 2014 


\section{HIGHLIGHTS}

- $\quad G N A S^{\mathrm{R} 201 \mathrm{C}}$ mutation supports transplantable HSC activity

- $\quad G N A S^{\mathrm{R} 201 \mathrm{C}}$ mutation sustains lymphoid-differentiation potential of long-term HSCs

- $\quad G N A S^{\mathrm{R} 201 \mathrm{C}}$ mutations may contribute to CHIP, but not necessarily hematopoietic transformation 
A

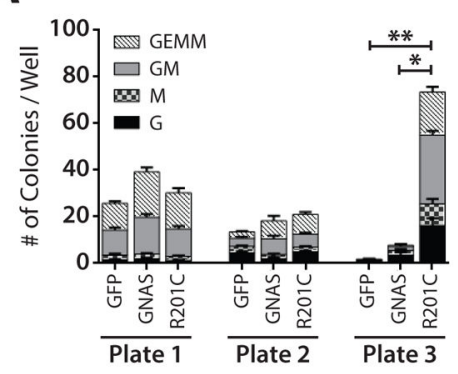

B

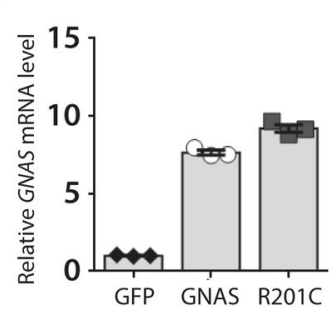

C

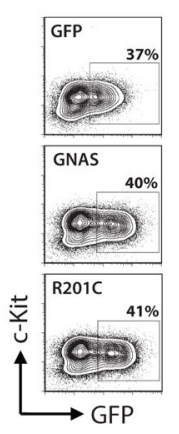

D

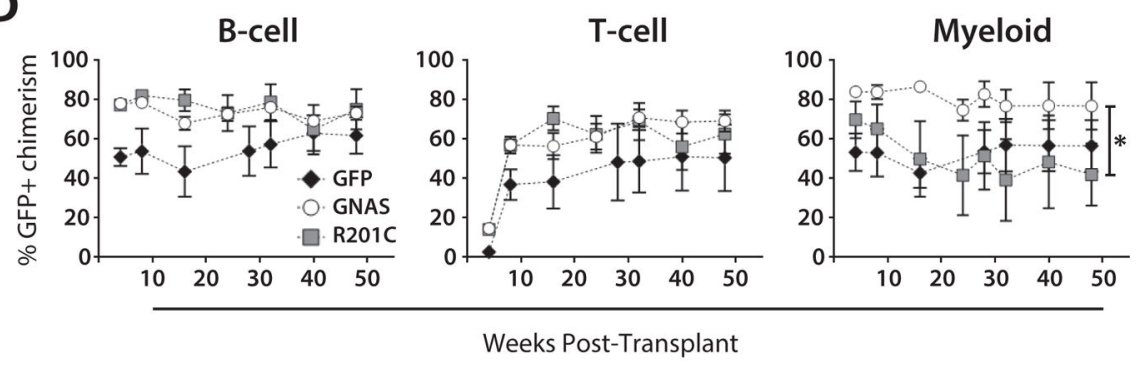

E
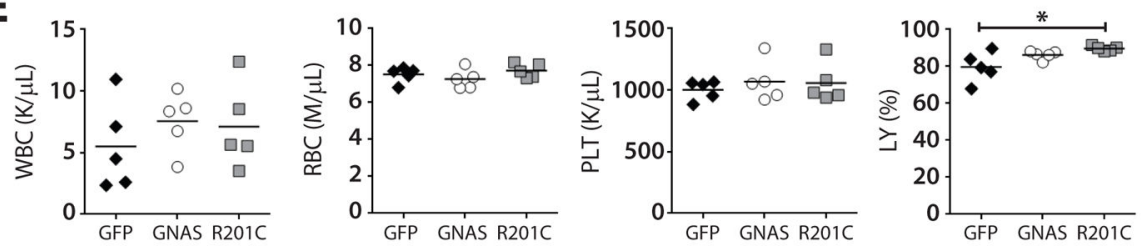

Figure 1. GNAS ${ }^{\text {R201C }}$ Does Not Induce Hematopoietic Disease

(A) Serial replating of HSCs transduced with control lentivirus (GFP), wild-type GNAS (GNAS) or $G N A S^{\mathrm{R} 201 \mathrm{C}}(n=4)$. (B) Relative mRNA expression level of $G N A S$ in HSCs transduced with the different lentiviruses. (C) Transduction efficiencies of bone marrow progenitor cells prior to transplantation. (D) Chimerism of GFP+ cells to blood lineages over a one-year transplant period $(n=5)$. (E) Blood cell counts of recipient mice one-year posttransplant. Mean \pm SEM values are shown. $* p<0.05$, ** $p<0.01$. 
A

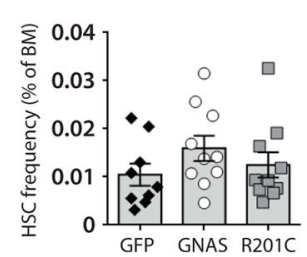

B

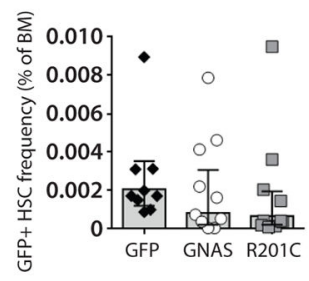

C
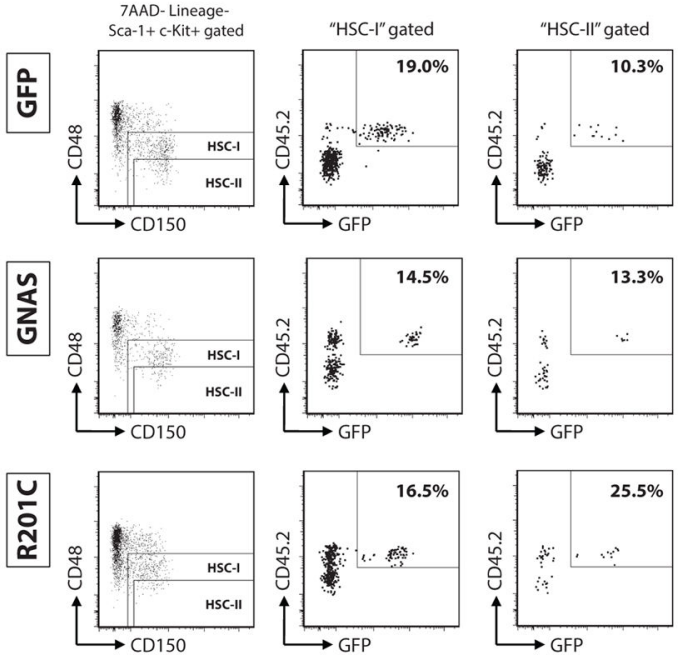

D

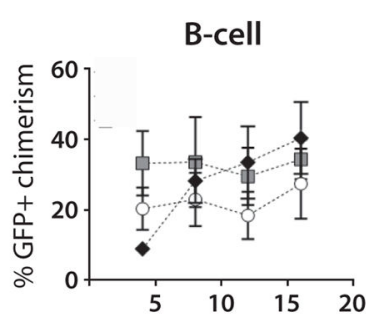

T-cell
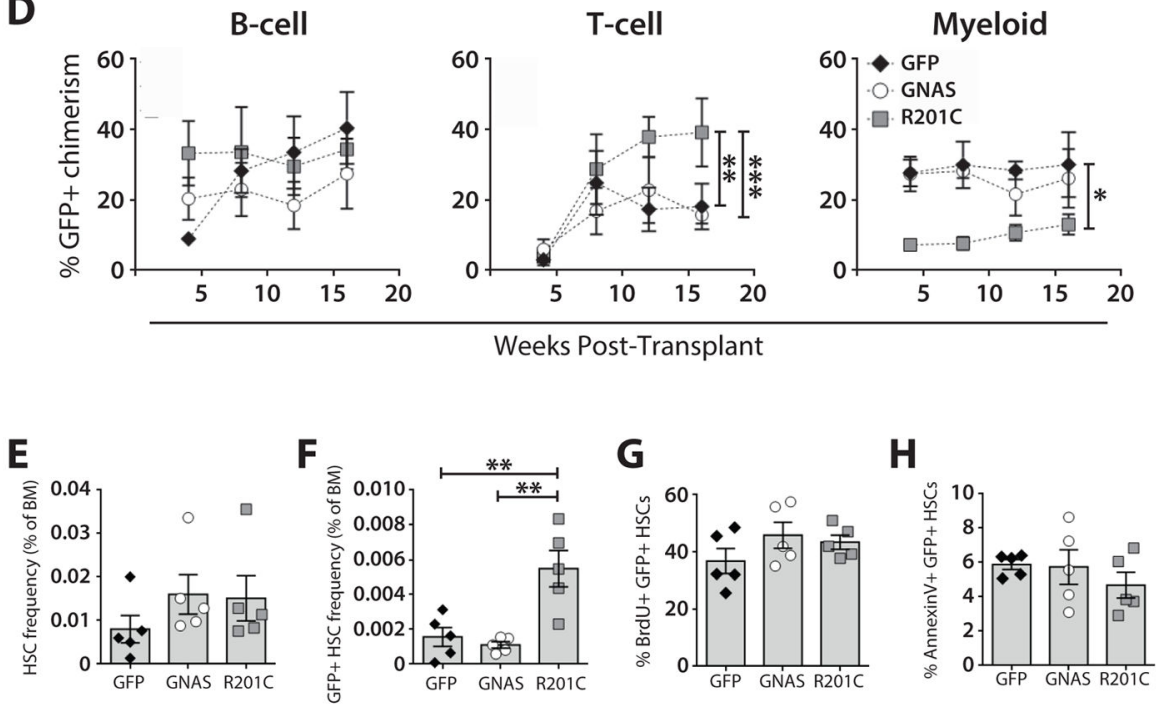

Figure 2. GNAS ${ }^{\text {R201C }}$ Maintains Transplantable HSC Activity and Preserve Lymphoid Potential Frequency of (A) total and (B) GFP+ HSCs (Lineage- Sca-1+ c-Kit+ CD48- CD150+) in the bone marrow of recipient mice 18-weeks post-transplant $(n=10-13)$. (C) More stringent gating on SLAM markers shows enrichment of $G N A S^{\text {R201C }}$ GFP+ HSCs. (D) Chimerism of transduced cells (GFP+) to myeloid, B-cell and T-cell blood lineages over a 16-week transplant period in secondary recipients. Frequency of (E) total and (F) GFP+ HSCs in secondary recipient bone marrow 18-weeks post-transplant. (G) Assessment of HSC proliferation by 72-hour BrdU incorporation. (J) Apoptosis in HSCs assessed by frequency of AnnexinV+ cells. Arithmetic mean \pm SEM values are shown, except for $2 \mathrm{~B}$ which shows geometric mean with $95 \%$ confidence intervals. $* p<0.05, * * p<0.01$. 
A

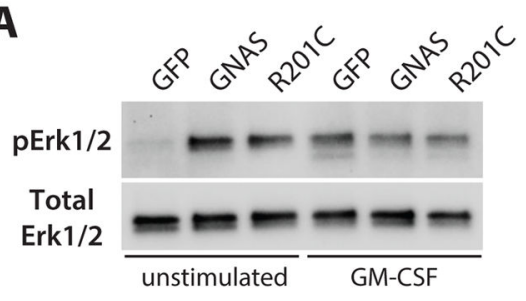

C

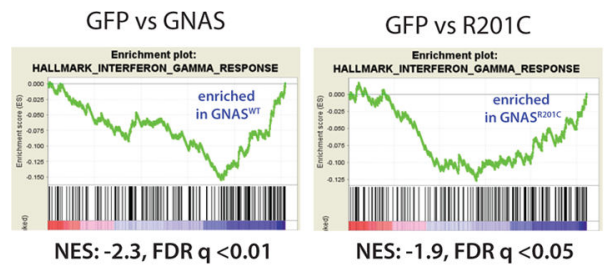

$\mathbf{E}$

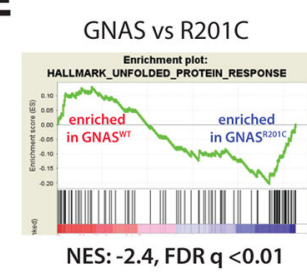

G

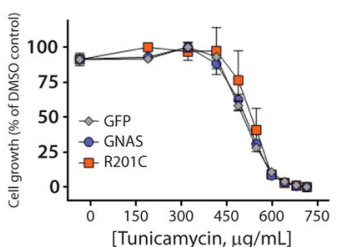

B

Relative $\log _{2}$ Fold

Expression Difference

-2.1012 $\frac{\text { GFP }}{123} \frac{\text { R201C }}{123} \frac{\text { GNAS }}{123}$

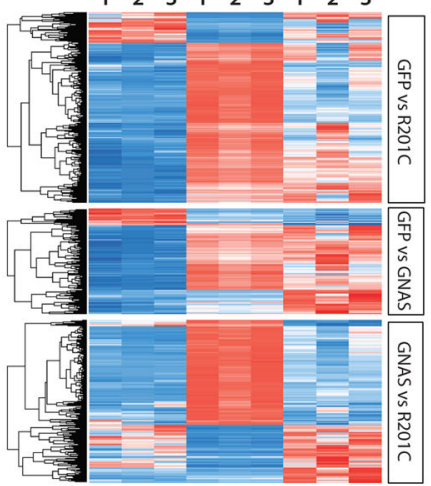

D

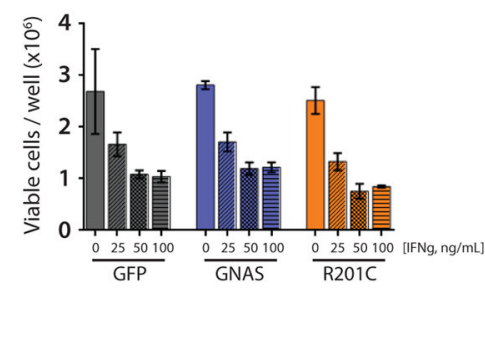

I

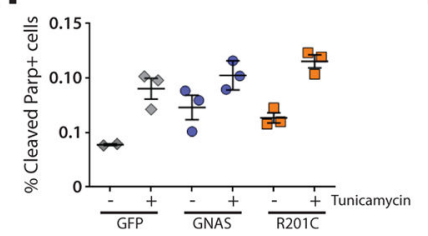

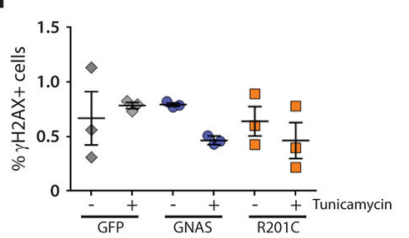

Figure 3. Molecular Pathways Regulated by GNAS ${ }^{\mathrm{R201C}}$ in HSCs

(A) Western blot of bone marrow GFP+ cells for pErk1/2 under basal conditions or after GM-CSF stimulation. (B) Supervised clustering analysis of differentially expressed genes from RNA-seq analysis. (C) GSEA plot showing enrichment for interferon gamma signaling in $G N A S$ and $G N A S^{\mathrm{R} 201 \mathrm{C}}$ HSCs. (D) Viable cell numbers of 32D cells stably expressing the indicated lentiviral constructs after 72-hours treatment with increasing concentrations of interferon gamma. (E) GSEA plot showing enrichment for unfolded protein response in $G N A S^{\mathrm{R} 201 \mathrm{C}}$ HSCs. (F) Expression of DNAjb9 in GFP, GNAS and $G N A S^{\mathrm{R} 201 \mathrm{C}} \mathrm{HSCs}$. (G) Relative cell growth of stable 32D cells with increasing concentrations of tunicamycin. (H) Assessment of apoptosis in stable 32D cells by cleaved Parp staining. (I) Assessment of DNA damage response in stable 32D cells by gH2AX staining. Mean \pm SEM values are shown $* * * p<0.001$. 